\title{
Distribution of megabenthic gastropods along environmental gradients: the mid-domain effect and beyond
}

\author{
Alvar Carranza ${ }^{1, *}$, Robert K. Colwell ${ }^{2}$, Thiago Fernando L. V. B. Rangel ${ }^{2}$ \\ ${ }^{1}$ Investigación y Desarrollo-Facultad de Ciencias, Iguá 4225, CP11400 Montevideo, Uruguay \\ ${ }^{2}$ Department of Ecology and Evolutionary Biology, University of Connecticut, Storrs, Connecticut 06269, USA
}

\begin{abstract}
We analysed the distribution patterns of megabenthic species of marine molluscs from the Uruguayan shelf in relation to 3 interacting gradients, namely depth, salinity and temperature of sea bottom waters. Our results were generated from a data set comprising the complete list of megabenthic gastropods (adult shell length $>50 \mathrm{~mm} ; 22$ species) from a study area that encompassed latitudes from 34 to $39^{\circ}$ south, between 4 and $800 \mathrm{~m}$ depth. Multiple regressions were used to evaluate the contribution of 3 classes of explanatory variables to gastropod richness at sampling points along the gradients: (1) geometric constraints on the distribution of species' tolerance ranges for environmental variables (the mid-domain effect, MDE), (2) the species-area effect driven by the spatial extent of scaled environmental variables, and (3) the environmental variables themselves. In addition, we explored multivariate explanations for the bathymetric pattern of gastropod species richness, incorporating depth-based area, temperature, salinity and geometric constraints as predictor variables. Examination of Moran's I for regression residuals confirmed that results were not biased by spatial autocorrelation. Overall, the environmental variables per se were the most important contributors to the observed patterns. However, a significant signature of the MDE was revealed, by the entry of geometric constraints into nearly all models. In contrast, the species-area effect was less important. These results suggest that: (1) MDE may operate in any kind of bounded gradient, (2) both stochastic and deterministic processes are responsible for the pattern observed, and (3) the relative contribution of the MDE to the patterns is dependent on the gradient considered and the way in which species richness is measured.
\end{abstract}

KEY WORDS: Mid-domain effect - Species richness - Continental shelf - Gastropods - Uruguay

\section{INTRODUCTION}

Species diversity gradients are among the most conspicuous ecological patterns and a major focus of ecological research. Globally, the number of species has been shown to decline poleward, peaking at the tropics in terrestrial, coastal marine and pelagic marine biotas. More than 30 evolutionary and ecological hypotheses have been proposed to explain this gradient of species diversity (Hawkins \& Diniz-Filho 2002, Arita 2005). In the marine realm, similar parabolic patterns have also been reported along bathymetric gradients for fish (Powell et al. 2003) and macro- and megafaunal invertebrate groups (polychaetes, cumaceans and bivalves) from the northwestern Atlantic (Gage \& Tyler 1991, Gage 1996).

Since humped patterns may be generated stochastically without the need to invoke the direct effects of environmental gradients, a growing body of research is focused on a particular approach that excludes all of the environmental, biological, or historical processes that might be causally linked to the observed patterns. Middomain effect theory (MDE; Colwell \& Hurtt 1994, Colwell \& Lees 2000) involves a null model that predicts 
that species ranges, when randomly arranged within a bounded domain, produce a unimodal curve with a mid-domain maximum (Colwell \& Lees 2000). To date, MDE models have been tested in several 1-dimensional gradients (i.e. latitude, depth, elevation, river courses) (Pineda 1993, Colwell \& Hurtt 1994, Grytnes \& Vetaas 2002, Sanders 2002, Brehm et al. 2007). In view of the fact that an overview of $21 \mathrm{MDE}$ studies (Colwell et al. 2004,2005 ) revealed a substantial signature of MDE in natural patterns, it seems possible to argue that stochastic geometric phenomena are indeed affecting (although in variable degrees) the patterns of species richness within any bounded domain. The only previous MDE-related study of marine gastropods (Pineda \& Caswell 1998) reported that a random rearrangement of species' ranges within geographic boundaries did not fully explain observed bathymetric patterns for deep sea gastropods and polychaetes in the western North Atlantic, but partial contributions of MDE to these patterns were not assessed.

In the present paper, we explore the extension of MDE null models to the assessment of the effect of geometric constraints on patterns of species richness along physiologically bounded environmental gradients of temperature and salinity, rather than within spatially bounded physical domains. The only previous such study that we are aware of is the work of Lusk et al. (2006), which examined the distribution of young trees along a light-availability gradient. Many environmental gradients are not geographically fixed because they are variable in time, like the salinity and temperature of seawater. Moreover, in patchy environments, environmental mosaics are more common than spatially continuous environmental gradients. Nonetheless, the environmental characteristics of the patches can be envisioned as mapping on continuous axes in niche space (Pulliam 2000, Rangel et al. 2007) that represent bounded range limits based on the physiological tolerances of species.

In estuaries, benthic organisms are commonly distributed along gradients of physiological stress according to their environmental tolerance (Remane \& Schlieper 1971). Day et al. (1989) related spatial differences in the composition of the benthic communities along estuarine gradients to changes in salinity, depth, sediment grain size and organic content. When compared with adjacent marine systems, estuaries are considered areas of low diversity, with high abundances (Atrill et al. 1996, Constable 1999). However, the idea that a humped pattern in species richness may emerge, given a sufficiently wide range encompassing variation in salinity from estuarine to oceanic environments, is supported by MDE predictions. Similarly, sea bottom temperature also shows conspicuous spatial gradients, being negatively correlated with depth and salinity.
Finally, water temperature is thought to be the principal limiting factor of the majority of shallow water habitats (e. g. Barnes \& Hughes 1988, Levinton 1995), and is thought to determine limits of biogeographical provinces in the southwestern Atlantic. For this reason, it is worthwhile to explore regional-scale patterns of specific richness in relation to temperature.

The large-scale environmental gradients associated with the interaction of the Río de la Plata estuary and oceanic water masses provide a unique opportunity to explore these relationships. The Río de la Plata flows into the Atlantic Ocean, with an average discharge of $22000 \mathrm{~m}^{3} \mathrm{~s}^{-1}$ (Framiñan \& Brown 1996, Guerrero et al. 1997, Ortega \& Martínez 2007). The ca. 200000 km² of the Uruguayan and the northern portion of Argentinean continental shelf (36 to $39^{\circ} \mathrm{S}_{\text {; Fig. }}$ ) ) are thus characterized by a singular hydrographical system affected by water masses of contrasting thermohaline characteristics, e.g. subantarctic waters (SAW), tropical waters (TW), subtropical waters (SW) and coastal waters $(\mathrm{CW})$. The last system $(\mathrm{CW})$, characterized by salinities $<33.2$, is principally a mixture of SAW and waters from the Río de la Plata estuary (e.g. Ortega \& Martínez 2007). These oceanographic features and their interaction with shelf topography are the main environmental structuring processes at a regional scale. In this context, the bathymetric gradient is associated with a sea bottom temperature gradient from $25^{\circ} \mathrm{C}$ in shallower waters to 4 to $5^{\circ} \mathrm{C}$ on the outer continental shelf and slope (e.g. Olivier \& Scarabino 1972, Carranza et al. 2008a,b).

In this area, megabenthic gastropods are a conspicuous faunistic component of the nearly uniform soft bottom habitats. The megabenthic gastropods provide a wide array of advantages for this kind of study. First, the presence of these long-lived, relatively low-motility animals in a particular place give us some confidence in their ability to tolerate local environmental conditions. Since seasonal variation within a given site sets the minimum breadth of tolerances required by individuals living at that site, relatively low-motility animals must be able to tolerate the full range of climatic conditions imposed by seasonal change. Second, their large size $(5 \mathrm{~cm}<$ maximum adult shell length < $40 \mathrm{~cm}$ ) makes it easy to document their presence, since gastropods are usually retained in most commercial fishing gear used in the study area. Third, their taxonomic status is well established, thus avoiding confusion regarding species misidentifications.

In the present study, we have described the patterns of diversity in megabenthic gastropods from the Uruguayan shelf in relation to the interacting salinity, temperature and bathymetric gradients. We have assessed the effect of geometric constraints on the observed diversity patterns in the context of multiple 


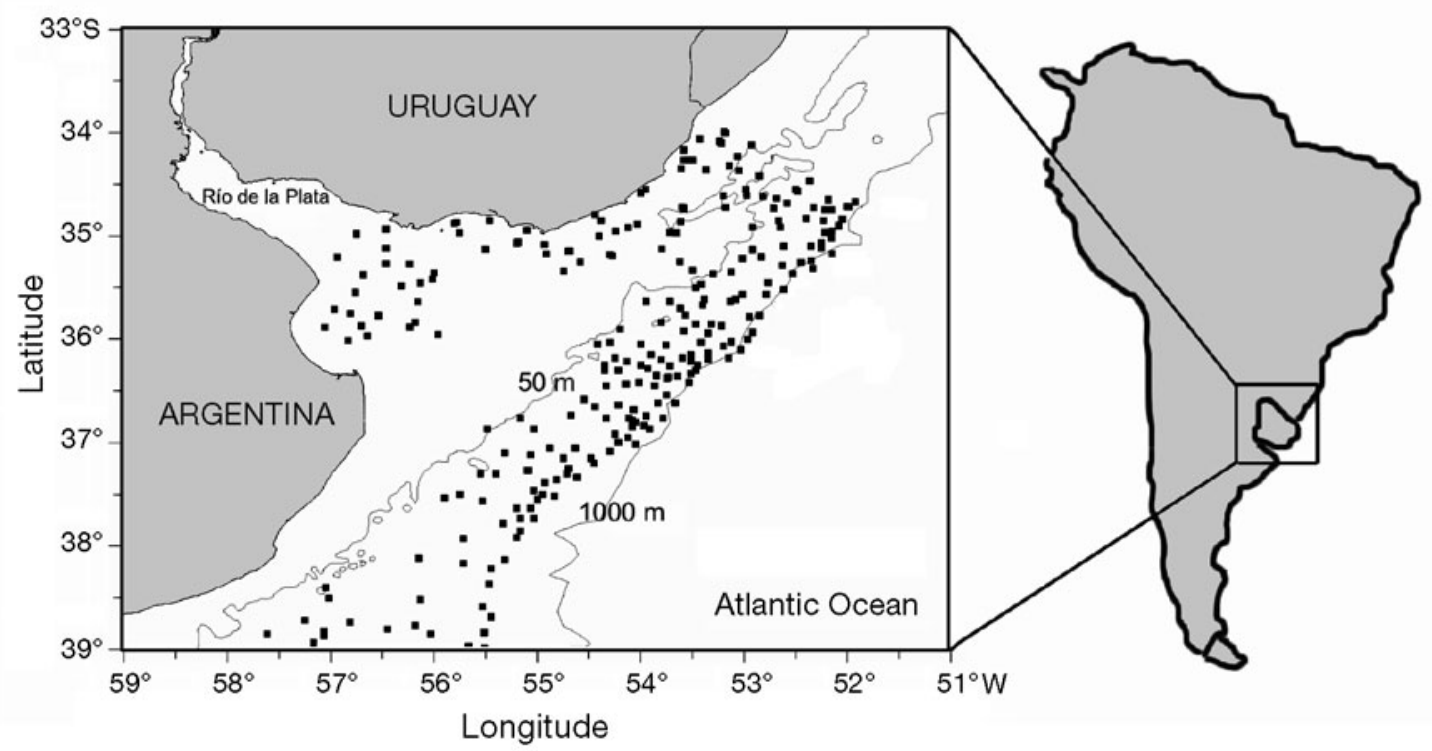

Fig. 1. Study area. The entire Uruguayan shelf and the northern portion of the Argentinean shelf are shown. Each point represents a trawling operation

causality with other candidate explanatory variables, including the environmental gradients themselves and the species-area relationship.

\section{MATERIALS AND METHODS}

Empirical data. Occurrence data for large gastropods ( $>5 \mathrm{~cm}$ adult shell length) were gathered from a total of 399 points in the study area, from 2 main sources: (1) previously unpublished data, obtained from 5 research cruises onboard RV 'Aldebaran' of the Uruguay National Directorate of Aquatic Resources (DINARA) and 2 cruises of commercial fishing vessels (Carranza 2006), and (2) published data that include the complete list of species collected during each trawl and the exact geographic locations of the operations (see Carranza et al. 2008a,b). The fishing gear used in the research vessel consisted of an Engel-type bottom trawl net with a $24 \mathrm{~m}$ horizontal opening and a $100 \mathrm{~mm}$ stretched mesh in the cod ends. The average duration of trawling operations was $0.5 \mathrm{~h}$. The exact locations of the stations were determined by global positioning system (GPS). Mean operational depth was calculated for each station, averaging initial and final depth of each trawl. In the commercial trawler, the gear used was quite similar, but the average duration of trawling operations was generally $>2 \mathrm{~h}$. Large gastropods were examined and identified to species in situ, either by the senior author or by F. Scarabino, malacological curator at the National Museum of Natural History of Uruguay. Species' concepts and nomenclature used here (detailed in Scarabino 2004 and references therein) can thus be checked for their accuracy from the voucher material deposited at this institution (Museo Nacional de Historia Natural y Antropología, Montevideo). Secondary data (i.e. those not collected directly by us) were carefully checked for taxonomy and accuracy of reported locations, taking particular consideration of the status (i.e. live collected or shells) of the material (see Bortolus 2008 for a full discussion on the links between taxonomy and ecological studies).

The presence/absence data were then binned in 47 quadrats of $0.5^{\circ} \times 0.5^{\circ}$, in order to accumulate all species observed in different hauls and to match the scale of the oceanographic information available. The number of gastropod species recorded within a quadrat is referred to here as 'observed richness'.

With these data, we were able to establish with relative accuracy the bathymetric, salinity and temperature ranges for each species in the area, assuming a continuous distribution within each domain (that is, along each environmental variable). This assumption is usually not a source of substantial bias for most taxa (Colwell et al. 2004) and would seem particularly reasonable for environmental, rather than geographical, gradients. For the bathymetric ranges, we used the direct observations of maximum and minimum depth where a particular species was recorded (when available), or checked the literature for existing data. For the salinity and temperature ranges, we used a different approach, since snapshot sampling does not provide information about the temporal variability in environmental conditions. For this reason, for each species record, we looked at the mean seasonal values of temperatures and salinity of the sea bottom in the pub- 
lished oceanographic information (Guerrero et al. 1997). The 2 extreme values were used as a conservative estimate of the temporal variability at each particular point. We repeated this procedure for each record and species, thus obtaining the overall extreme values for the environmental variables in each species' distribution along these variables. These extreme values were considered as an estimate of the species' physiological tolerance to the physical variables involved. Once the bathymetric, salinity and temperature ranges for each species were obtained, we estimated species richness at regularly spaced points along the gradients as the number of species that had intersecting ranges at that point. The resulting richness values for each gradient are referred to here as 'interpolated richness'.

Spatial analysis. Biodiversity data are usually strongly spatially structured (spatially autocorrelated), driven by environmental factors and/or dispersal mechanisms. Spatial autocorrelation can be defined as 'the property of random variables taking values, at pairs of locations a certain distance apart, that are more similar (positive autocorrelation) or less similar (negative autocorrelation) than expected for randomly associated pairs of observations' (Legendre 1993, p. 1659). Whereas spatial autocorrelation presents an interesting opportunity for biological investigations, it can also be a source of model misspecification because sampling units close to each other are partially redundant with respect to the information they provide. Thus, the number of degrees of freedom (based on the number of sampling points) is overestimated, and, consequently, confidence intervals are much narrower and Type I errors are inflated.

In the present study, we used Moran's I (a distanceweighted correlation coefficient used to detect departures from spatial randomness) to measure the spatial autocorrelation in the regression residuals, treating the latitude and longitude centroid of each sampling quadrat as the $x$ - and $y$-coordinates. When regression residuals are spatially autocorrelated, an explicit spatial regression is needed, in order to control for bias that spatially structured data may cause. However, when regression residuals are not spatially autocorrelated, further analysis by spatial regression is not necessary or informative (Diniz-Filho et al. 2002). All spatial statistics were carried out using SAM v.1.1 (Rangel et al. 2006), freely available at www.ecoevol.ufg.br/sam.

Null models. To estimate predicted richness under the assumption of random placement of interpolated richness, we drew ranges at random from the empirical range size frequency distribution (RSFD) and placed them randomly within each unidimensional physiological domain (Model 4 of the computer application RangeModel 5, see Colwell 2008). Resampling RSFDs balances the risk of underestimating and overestimat- ing the role of MDE (Colwell et al. 2004). We chose to truncate empirical physiological ranges that may extend beyond the physiological domain limits represented in the study area, treating the portion occurring within the domain as endemic. However, due to our limited understanding of the biology of range formation, no obvious correct choice exists regarding how the model should be implemented (see McClain et al. 2007). Ordinary least-squares regressions (OLS) were performed to assess the fit between richness predicted by the geometric constraints model and interpolated empirical richness. The predicted distribution of species richness along each gradient was then used in multiple regression analysis (see below), in order to incorporate MDE as an explanatory variable on an equal statistical footing with other candidate explanatory variables.

Gradient structure and species-area effect. We examined whether a simple species-area relationship contributed to the observed patterns. On the Uruguayan continental shelf, the frequency distribution of environments with regard to depth, salinity and temperature is highly skewed: for example, the $50 \mathrm{~m}$ isobath separates 2 areas of approximately equal size, the remaining $100 \mathrm{~m}$ depth categories being represented by increasingly less area. To evaluate the possible contribution of area to species richness, we partitioned the gradients into regular spatial intervals on an arithmetic scale and constructed the frequency distribution of each environmental variable, using as a unit of area the $0.5^{\circ}$ quadrats, roughly equivalent to $2600 \mathrm{~km}^{2}$.

Multivariate analysis. Using multiple regression analysis, we explored 4 sets of candidate variables to assess the roles of depth, salinity, temperature, geometric constraints (MDE) and area as explanatory factors for species richness. We used the number of $0.5^{\circ}$ quadrats in the bins of a frequency distribution of each environmental variable (depth, salinity and temperature) as an estimate of the amount of map area characterized by different levels of each environmental factor. The depth model included depth, depth-specific area and geometric constraints as candidate explanatory variables, whereas the salinity model included salinity, salinity-specific area and geometric constraints, and the temperature model included temperature, temperature-specific area and geometric constraints. The fourth model, the all gradients model, included salinity, temperature, depth-specific area and geometric constraints as candidate explanatory variables.

For each of the 4 sets of candidate variables, we selected the best model from among all possible combinations of simple variables, choosing the model that minimized the Akaike information criterion (AIC) statistic (Burnham \& Anderson 1998). Regression residu- 
als were examined for spatial autocorrelation based on Moran's $I$, based on a connectivity matrix constructed using a distance criterion, with connections weighted by the inverse of the distance between points (lag distance $=50 \mathrm{~km}$ ). To assess levels of collinearity in our data set, we calculated the condition number for each matrix of explanatory variables. The condition number can be calculated as the square root of the ratio between the largest and smallest eigenvalues of the matrix of explanatory variables. Values of the condition number $<30$ are usually interpreted as acceptable levels of multicolinearity (Weisberg 1985).

\section{RESULTS}

Species richness of megabenthic gastropods (22 species) in the study area is patchily distributed in space (Fig. 2), with a roughly NW-SE gradient that extends throughout the continental shelf. The area under the influence of the discharge of Río de la Plata and the shelf break are characterized by low richness, whereas intermediate areas in the marine portion of the shelf showed the highest values of species richness.

Plots of observed species richness and species richness predicted by the MDE models for each of the 3 different environmental domains in the South Atlantic Ocean appear in Fig. 3. Interpolated species richness patterns varied among the 3 domains. In spite of differences in shape, most of the empirical values lay within the $95 \%$ confidence intervals generated by the MDE predictions for temperature and for depth, but not for the salinity domain.

Observed species richness for the bathymetric domain showed a peak in species richness towards the

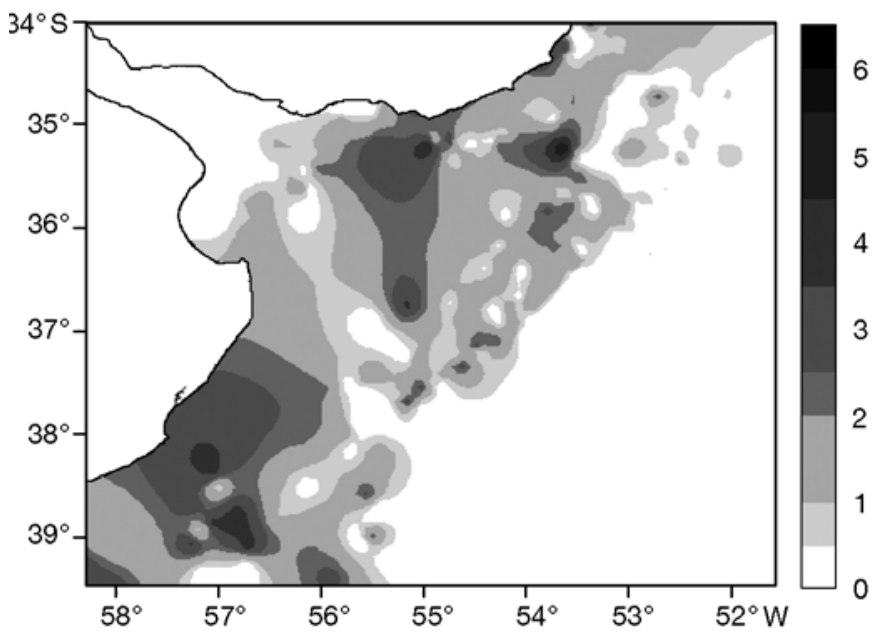

Fig. 2. Species richness map for the study area. Interpolation was performed using point kriging. Shade bar: species richness (no. of species) shallow end (100 to $200 \mathrm{~m}$ ) (Fig. 3a). As depth increased, there was a general trend for richness to decrease linearly. A simple linear regression for the predicted versus observed species richness patterns for the bathymetric domain showed that geometric constraints accounted for only $16 \%$ of the variance, not accounting for other candidate explanatory variables. Species richness along the salinity domain (Fig. 3b) shows a pattern that is sharply skewed towards the
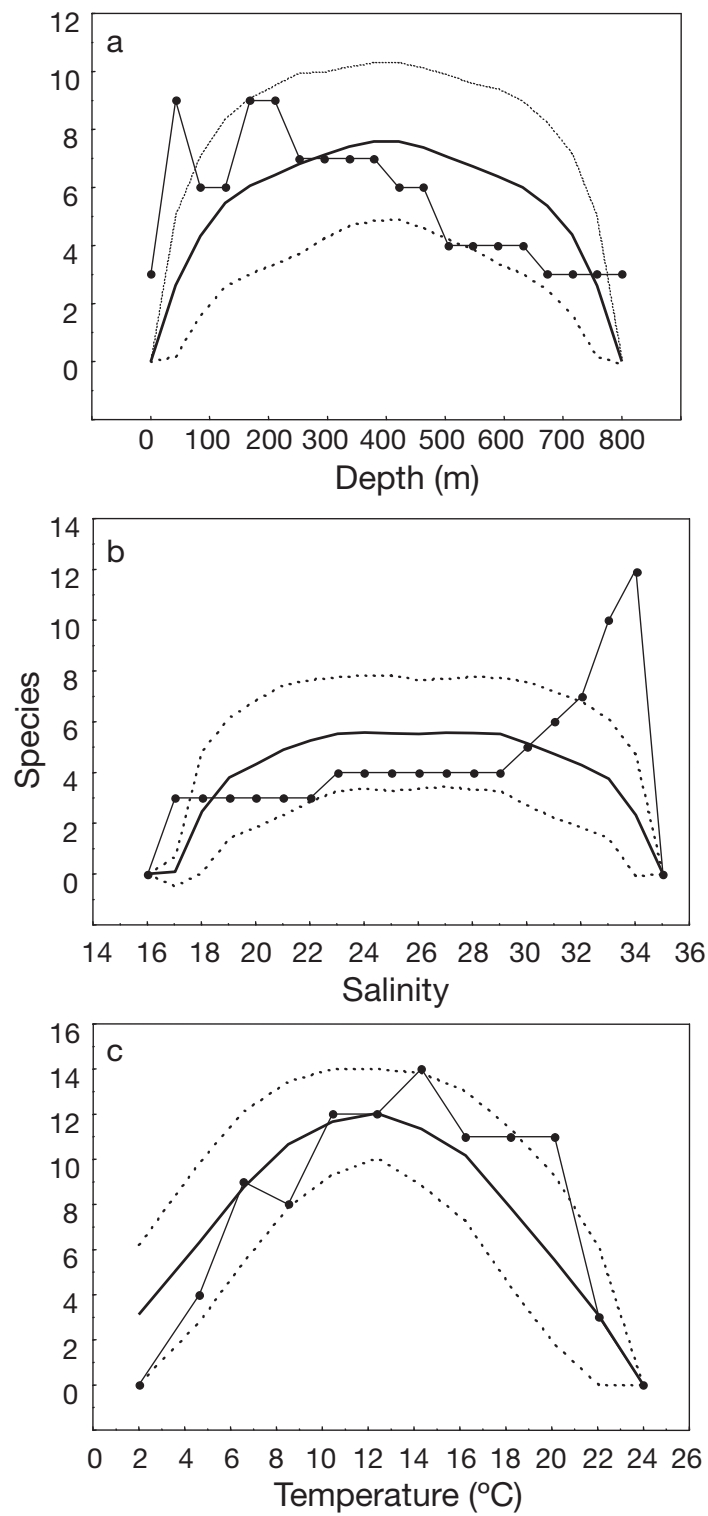

Fig. 3. Observed and predicted species richness curves for megabenthic gastropods on the southwestern Atlantic shelf off Rio de la Plata for: (a) depth, (b) salinity and (c) temperature. Points connected by a solid line: the empirical species richness curve; solid line (no points): the expected species richness curve generated by the mid-domain effect (MDE) model $_{i}$ broken lines: the $95 \%$ confidence intervals for MDE predictions 
more saline end, with a distinct peak in the observed data lying substantially outside the $95 \%$ confidence intervals generated by the null model. The MDE model is shown by the linear regression to account for $<5 \%$ of the variance in salinity values. The observed distribution of species richness along the temperature gradient showed a peak located in the mid-portion of the
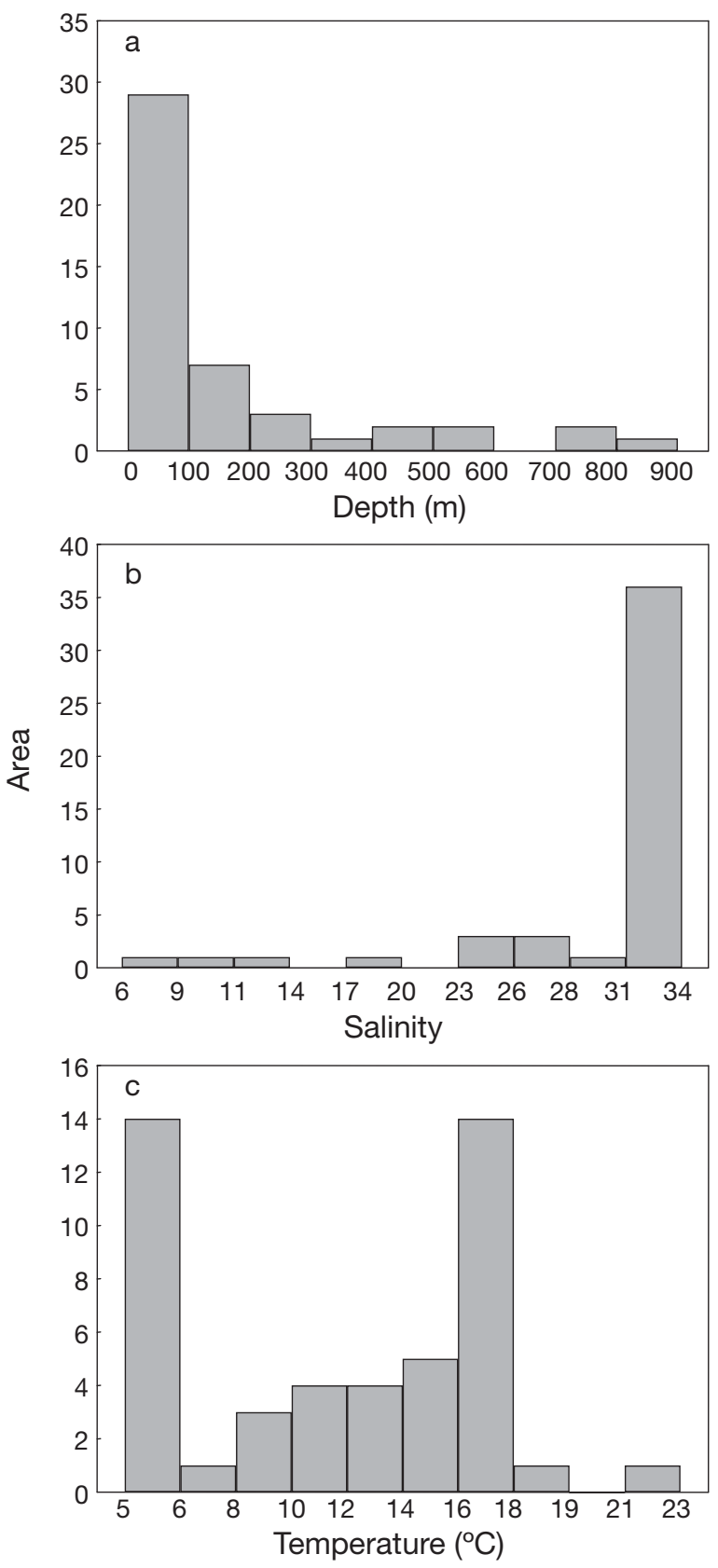

Fig. 4. Spatial frequency distribution of environments with regard to: (a) depth, (b) salinity and (c) temperature. Each histogram shows the distribution of map space within each category of the environmental variable. $y$-axis units represent a quadrat of approximate area $=2600 \mathrm{~km}^{2}, x$-axis values are rounded to the nearest integer domain $\left(10\right.$ to $\left.14^{\circ} \mathrm{C}\right)$ (Fig. 3c). The observed data showed an approximately parabolic pattern of species richness. For the temperature domain, the MDE model explains $74 \%$ of the variance as shown by the simple linear regression. Regression residuals were not significantly spatially autocorrelated in any of these analyses (all Moran's $I<0.231$, for all distance classes).

The distributions of map area in relation to each gradient are shown in Fig. 4. Table 1 reports the results of model selection for multiple regressions of richness measures on the environmental variables and MDE predictions. In each case, the model with the lowest AIC is reported (best model). Overall, interpolated richness performed better than observed richness (nearly 4 -fold more variance accounted for by the best model). Models based on interpolated richness along the salinity and temperature gradients showed higher $\mathrm{r}^{2}$ than bathymetric gradients. In contrast, the explanatory power of statistical models for observed richness was very similar for the 3 gradients (range 14 to $15 \%$ variance). These differences persisted in the spatial

Table 1. Multiple regression analysis of observed species richness and interpolated species richness versus 2 environmental factors (area and gradient) and geometric constraints (mid-domain effect model predictions) for each environmental gradient (spatial mode, individual gradients) and for all gradients and geometric constraints considered together (spatial model, all gradients). Model selection (best model) for multiple regressions (regression residuals were not affected by spatial autocorrelation) was based on minimizing the Akaike information criterion (AIC), with consideration of all possible models. Beta $(\beta)$ is the standardized regression slope for each factor in the best model

\begin{tabular}{|lcc|}
\hline \multicolumn{3}{|c|}{ Spatial model (individual } \\
Multiple regression & $\begin{array}{c}\text { Observed } \\
\text { richness }\end{array}$ & $\begin{array}{c}\text { Interpolated } \\
\text { richness }\end{array}$ \\
\hline Depth gradient & & \\
Best model $\left(\mathrm{r}^{2}\right.$, AIC) & $0.146,64.575$ & $0.461,49.877$ \\
Depth $(\beta)$ & 0.32 & 0.65 \\
Geometric constraints $(\beta)$ & 0.357 & 0.55 \\
Salinity gradient & & \\
Best model ( ${ }^{2}$, AIC) & $0.156,61.601$ & $0.779,50.555$ \\
Area $(\beta)$ & & 0.52 \\
Salinity $(\beta)$ & 0.395 & 0.46 \\
Geometric constraints $(\beta)$ & & 0.037 \\
Temperature gradient & & \\
Best model ( $\mathrm{r}^{2}$, AIC) & $0.145,64.605$ & $0.742,35.724$ \\
Area $(\beta)$ & & 0.252 \\
Temperature $(\beta)$ & 0.46 & 0.65 \\
Geometric constraints $(\beta)$ & 0.558 & 1.12 \\
All gradients & & \\
Best model ( ${ }^{2}$, AIC) & $0.29,58.087$ & $0.61,40.054$ \\
Salinity $(\beta)$ & 0.596 & 0.704 \\
Temperature $(\beta)$ & 0.631 & 0.584 \\
Geometric constraints $(\beta)$ & 0.387 & 0.863 \\
Area $(\beta)$ & & 0.61 \\
& & \\
\hline
\end{tabular}


model that considered all gradients together. Geometric constraints entered in 4 models (1 beta not significant) for interpolated richness and 3 models for observed richness. In contrast, the species-area effect seems to be much less important, entering only 3 models for interpolated richness and none for observed richness. All environmental factors were important contributors in all cases, the strength of the relationships differing considerably depending upon the measure of species richness, but generally showed the same tendencies. Examination of Moran's I for distance-class residuals from the multiple regressions for the models selected using the AIC did not show substantial spatial autocorrelation. The condition number for the matrices of explanatory variables were very low (salinity model: 3.872; depth model: 4.912; temperature model: 2.646; spatial model, all gradients: 6.213), indicating that multicollinearity is not an issue for our analyses, since all values are well below the level of 30 considered to indicate substantial collinearity (Weisberg 1985).

\section{DISCUSSION}

The finding that a stochastic rearrangement of species ranges on a bounded domain generates a pattern in which species richness peaks at the middle of 1dimensional domains, declining towards the borders following a parabolic curve, has repeatedly been demonstrated for several geographic gradients (see Colwell et al. 2004, Arita 2005). In the present paper, we extended the use of MDE models to stress gradients (in the sense of Chase \& Leibold 2003), showing that a random re-shuffling of empirical tolerance ranges generated the characteristic parabolic pattern for 1dimensional MDE models. Overall, both geometric constraints and environmental effects outweighed species-area effects. For interpolated richness, MDE was the most important contributor (spatial model, all gradients), whereas temperature showed the largest effect on observed richness. Interpolated richness, however, may overestimate the presence of a species in a given habitat, since species are often present in unsuitable habitats and absent from suitable habitats (Pulliam 2000), and, if unjustified, will inflate MDE predictions (Grytnes \& Vetaas 2002). Conversely, observed richness may fail to detect a species in a particular place due to patchy distributions, insufficient sampling, or simply random sampling error. Both kinds of potential error must be taken into account when analysing differences in empirical patterns emerging from different measures of species richness. Interpolated richness, however, does not affect species range size, since species ranges were derived from empirical observations and not from theoretical models. In this vein, species ranges are more likely to have been underestimated than overestimated. This is a conservative bias for MDE, as the overestimation of species ranges increases the strength of the MDE predictions (due to the disproportionate effect of species with large ranges in the model outcome).

The degree to which the empirical data match the MDE model and thus can be ascribed to 'geometric constraints' is highly variable among studies (Pineda \& Caswell 1998, Colwell \& Lees 2000, Colwell et al. 2004). Findings of certain hump-shaped patterns of species richness documented across the depth gradient may be largely ascribed to a mid-domain effect (Gage \& Tyler 1991, Colwell \& Lees 2000), whereas other data sets do not fully meet the assumptions of the null models (North Atlantic deep sea fishes; Kendall \& Haedrich 2006). In this vein, as suggested by Colwell et al. (2004), MDE models are not null hypotheses to be simplistically rejected or accepted. Thus, MDE should be assessed on an equal statistical footing with other candidate explanations for richness within the context of multiple causality. In the present study, the same multivariate data set displayed 3 different responses to the gradients co-occurring at the study area; MDE was conspicuous along the temperature gradient, but was less important on the bathymetric gradient and almost nil in the saline gradient.

Given the vast amount of space potentially suitable for establishment of shallow-water species (Fig. 4a), the species-area relationship seemed a plausible a priori hypothesis to explain this pattern, with conditions that cover a larger spatial extent expected to support more species than less common conditions. However, this conjecture was not supported by the regression analysis. Geometric constraints, on the other hand, were found to be an important contributor to the observed patterns. In general, there is some agreement that the bathymetric increase in diversity within the inner shelves is linked to a decrease in variability of the environment (Boltovskoy 1981 as cited in Fortes \& Absalão 2004), favouring a higher species richness in deeper waters. In support of this view, Fortes \& Absalão (2004) showed a positive relationship between bathymetric range locations and the bathymetric gradient for South Atlantic gastropods; this should lead to a higher than expected species richness in deeper areas. The apparent lack of concordance with our study may be ascribed to the fact that we limited our study to the well-sampled megagastropods (22 species), whereas Fortes \& Absalão (2004) studied a much higher species number (4097 species), including both large- and small-bodied gastropods. On the other hand, the combination of higher productivity, warmer temperatures and a full saline gradient may lead to a 
higher diversity in the shallower environments of our study area.

The empirical distribution of both interpolated and observed species richness along the saline gradient, on the other hand, did not show the signature of MDE, suggesting that strong deterministic factors may be influencing the shape of the relationship between species richness and salinity. Examination of patterns showed a distinctly positive relationship of species richness with salinity for values $>29$. This increase in richness with salinity can be explained because lower salinity also implies greater temporal variation as it is associated with the estuarine regime operating at the inner shelf. Environmental osmotic stress may be affecting the number of species able to tolerate estuarine conditions. In addition, areas with salinities ranging from 30 to 35 occupied $78 \%$ of the available space (Fig. 4b). This result suggests that a set of processes (both physiological and ecological) may operate together to determine the observed pattern. For the distribution of species richness along the temperature domain most of the observed variance is generated by a pattern of ranges in relation to temperature that does not differ substantially from random range placement under geometric constraints set by fixed physiological limits. We stress that this pattern is the statistical outcome of deterministic evolutionary and ecological processes at the level of individuals and populations (Colwell \& Lees 2000).

Finally, some methodological constraints must be taken into account. The definition of a hard boundary following Colwell \& Hurtt (1994) is 'a point beyond which species ranges cannot extend'. Although middomain models have now been extended to more 'permeable' boundaries (Connolly 2005), MDE curves are nonetheless sensitive to their placement, so that caution must be exercised in defining domain limits. Two implicit assumptions may lead to a failure in interpretation of distributional data in defining domain limits. The first is that the current distribution of a species is representative of its basic habitat requirements; the second is that these requirements remain relatively invariant through time (Pearson \& Dawson 2004). We do not pretend to deal here with the uncertainty associated with this issue, but it is an important caveat for all the domains we have treated. To what extent the empirical range distributions define the full extent of the 'realized' species niche is difficult to ascertain. In this context, identifying domain boundaries is often difficult, as pointed out by McClain \& Etter (2005). These authors stated that randomly generated bathymetric species diversity patterns for gastropods, bivalves and polychaetes in the North American Basin differ significantly from the empirical patterns. They also demonstrated how differences in assigned bound- aries, the generating algorithms and distribution characteristics (i.e. patchiness) influenced the output of the null model. For our study, the boundaries for each domain (temperature, salinity and depth) were set on the basis of the maximum and minimum observed values. This, of course, does not imply that species ranges cannot possibly extend further, at least for 1 of the 2 boundaries. While the absolute lower limits of the domain (e.g. $0 \mathrm{~m}$ depth, 0 psu, $0^{\circ} \mathrm{C}$ ) may constitute truly 'hard' physiological boundaries to species distribution, upper limits are in some cases more relaxed, at least within the domain examined. For example, our maximum depth $(800 \mathrm{~m})$ was set on the basis of the deepest oceanographic station monitored, but records for some species indicate that their bathymetric distribution may reach $>1000 \mathrm{~m}$ depth. This discrepancy may be seen as artificially biasing the bathymetric range so the midpoint lies in a shallower position. McClain et al. (2007) listed 3 approaches commonly used for dealing with non-endemic species (i.e. species whose ranges are only partially contained within the analysed domain). These are: (1) exclude them entirely from all analyses (Colwell \& Lees 2000, Jetz \& Rahbek 2001), (2) truncate the range at the domain edge and treat the portion occurring within the domain as endemic (Diniz-Filho et al. 2002, McCain 2003), and (3) truncate the range at the domain edge and force these non-endemic range fragments to remain attached to a domain edge during randomization (Colwell et al. 2004). Although Colwell et al. (2004) pointed out that this decision does not strongly affect MDE model fits to the data studied prior to their review, McClain et al. (2007) suggested that this can affect the general shape and magnitude of the predicted relationship. According to these authors, our approach will produce stronger richness peaks than the third approach. In the study model, however, the number of non-endemic species in relation to depth ranges is presumably low. Salinity, on the other hand, rarely exceeds 35 psu in the modern ocean, and, in this case, the upper domain limit seems to be in agreement with the hard boundary condition. To what extent these uncertainties reduce the utility of the mid-domain models, and the degree to which they are useful for any given domain variable in any arbitrary set of observations remain open questions.

Acknowledgements. This work was part of the $\mathrm{PhD}$ thesis of A.C. supported by PEDECIBA and ANII (Uruguay). Special thanks to F. Scarabino (Museo Nacional de Historia Natural y Antropología and DINARA, Uruguay) and Dr. Bernhard Hausdorf (curator at the Zoologisches Museum der Universitaet Hamburg, Germany), who provided invaluable data and relevant bibliographical material. Two anonymous referees helped to improve the manuscript. T.F.L.V.B.R. was supported by a Fulbright/CAPES fellowship (15061630-2668/05-0) and 
by the University of Connecticut. R.K.C. and T.F.L.V.B.R. were supported by the US National Science Foundation (DEB-0639979). A.C. thanks Marina and Estela for encouragement and support.

\section{LITERATURE CITED}

Arita HT (2005) Range size in mid-domain models of species diversity. J Theor Biol 232:119-126

Atrill M, Ramsay P, Thomas Myles R, Trett M (1996) An estuarine biodiversity hot-spot. J Mar Biol Assoc UK 76: 161-175

Barnes RSK, Hughes R (1988) Speciation and biogeography. In: An introduction to marine ecology. Blackwell Scientific Publications, Oxford, p 351

Boltovskoy D (1981) Atlas del zooplancton del Atlántico sudoccidental y métodos de trabajo com el zooplancton marino. INIDEP, Mar del Plata, as cited in Fortes \& Absalão (2004)

Bortolus A (2008) Error cascades in the biological sciences: the unwanted consequences of using bad taxonomy in ecology. Ambio 37:114-118

Brehm G, Colwell RK, Kluge J (2007) The role of environment and mid-domain effect on moth species richness along a tropical elevational gradient. Glob Ecol Biogeogr 16: 205-219

Burnham KP, Anderson DR (1998) Model selection and inference: a practical information-theoretic approach. SpringerVerlag, New York

Carranza A (2006) Large gastropods by-catch in the Hake fishery at the Argentinean-Uruguayan common fishing zone. Comun Soc Malacol Urug 9:61-67

Carranza A, Scarabino F, Ortega L (2008a) Distribution of large benthic gastropods in the Uruguayan continental shelf and Río de la Plata estuary. J Coast Res 24:161-168

- Carranza A, Scarabino F, Brazeiro A, Ortega L, Martínez S (2008b) Assemblages of megabenthic gastropods from Uruguayan and northern Argentinean shelf: spatial structure and environmental controls. Cont Shelf Res 28:788-796

Chase JM, Leibold MA (2003) Ecological niches. Linking classical and contemporary approaches. University of Chicago Press, Chicago, IL

Colwell RK (2008) RangeModel: tools for exploring and assessing geometric constraints on species richness (the mid-domain effect) along transects. Ecography 31:4-7

Colwell RK, Hurtt GC (1994) Nonbiological gradients in species richness and a spurious Rapoport effect. Am Nat 144: 570-595

Colwell RK, Lees DC (2000) The mid-domain effect: geometric constraints on the geography of species richness. Trends Ecol Evol 15:70-76

- Colwell RK, Rahbek C, Gotelli N (2004) The mid-domain effect and species richness patterns: What have we learned so far? Am Nat 163:E1-E23

> Colwell RK, Rahbek C, Gotelli N (2005) The mid-domain effect: there's a baby in the bathwater. Am Nat 166: E149-E154

Connolly SR (2005) Process-based models of species distributions and the mid-domain effect. Am Nat 166:1-11

Constable AJ (1999) Ecology of benthic macro-invertebrates in soft-sediment environments: a review of progress towards quantitative models and predictions. Aust J Ecol 24:452-476

Day JW Jr, Hall C, Kemp WM, Yanez-Arancibia A (1989) Estuarine ecology. John Wiley and Sons, New York

Diniz-Filho JAF, de Santána CER, de Souza MC, Rangel TF
(2002) Null models and spatial patterns of species richness in South American birds of prey. Ecol Lett 5:47-55

Fortes RR, Absalão RS (2004) The applicability of Rapoport's rule to the marine molluscs of the Americas. J Biogeogr 31: 1909-1916

> Framiñan MB, Brown OB (1996) Study of the Río de la Plata turbidity front. I: spatial and temporal distribution. Cont Shelf Res 16:1259-1282

> Gage JD (1996) Why are there so many species in deep-sea sediments? J Exp Mar Biol Ecol 200:257-286

Gage JD, Tyler PA (1991) Deep sea biology. A natural history of organisms at the deep sea floor. Cambridge University Press, Cambridge

Grytnes JA, Vetaas OR (2002) Species richness and altitude: a comparison between null models and interpolated plant species richness along the himalayan altitudinal gradient, Nepal. Am Nat 159:294-304

Guerrero RA, Acha EM, Framiñan MB, Lasta CA (1997) Physical oceanography of the Río de la Plata estuary, Argentina. Cont Shelf Res 17:727-742

Hawkins BA, Diniz-Filho JAF (2002) The mid-domain effect cannot explain the diversity gradient of Nearctic birds. Glob Ecol Biogeogr 11:419-426

Jetz W, Rahbek C (2001) Geometric constraints explain much of the species richness pattern in African birds. Proc Natl Acad Sci USA 98:5661-5666

Kendall VJ, Haedrich RL (2006) Species richness in Atlantic deep-sea fishes assessed in terms of the mid-domain effect and Rapoport's rule. Deep-Sea Res I 53:506-515

- Legendre P (1993) Spatial autocorrelation: Trouble or new paradigm? Ecology 74:1659-1673

Levinton JS (1995) Biotic diversity in the ocean. In: marine biology function, biodiversity, ecology. Oxford University Press, New York

Lusk CH, Chazdon RL, Hofmann G (2006) A bounded null model explains juvenile tree community structure along light availability gradients in a temperate rain forest. Oikos 112:131-137

> McCain CM (2003) North American desert rodents: a test of the mid-domain effect in species diversity. J Mammal 84: 967-980

McClain CR, Etter RJ (2005) Mid-domain models as predictors of species diversity patterns: bathymetric diversity gradients in the deep sea. Oikos 109:555-566

McClain CR, White EP, Hurlbert AH (2007) Challenges in the application of geometric constraint models. Glob Ecol Biogeogr 16:257-264

Olivier SR, Scarabino V (1972) Distribución ecológica de algunos moluscos recogidos por la expedición del 'Walter Herwig' (R.F.A.) al Atlántico sudoccidental (1966). Rev Bras Biol 32:235-247

> Ortega L, Martínez A (2007) Multiannual and seasonal variability of water masses and fronts over the Uruguayan shelf. J Coast Res 23:618-629

> Pearson RG, Dawson TE (2004) Bioclimate envelope models: what they detect and what they hide-response to Hampe (2004). Glob Ecol Biogeogr 13:471-473

Pineda J (1993) Boundary effects on the vertical ranges of deep-sea benthic species. Deep-Sea Res I 40:2179-2192

Pineda J, Caswell H (1998) Bathymetric species-diversity patterns and boundary constraints on vertical range distributions. Deep-Sea Res II 45:83-101

Powell SM, Haedrich RL, McEachran JD (2003) The deep-sea demersal fish fauna of the northern Gulf of Mexico. J Northwest Atl Fish Sci 31:19-33

> Pulliam HR (2000) On the relationship between niche and distribution. Ecol Lett 3:349-361 
Rangel TFLVB, Diniz-Filho JAF, Bini LM (2006) Towards an integrated computational tool for spatial analysis in macroecology and biogeography. Glob Ecol Biogeogr 15: 321-327

Rangel TFLVB, Diniz-Filho JAF, Colwell RK (2007) Species richness and evolutionary niche dynamics: a spatial pattern-oriented simulation experiment. Am Nat 170: 602-616

Remane A, Schlieper C (1971) Biology of brackish water. John

Initial editorial responsibility: Howard Browman, Storebø, Norway; Final editorial responsibility: Matthias Seaman,

Oldendorf/Luhe, Germany
Wiley and Sons, New York

Sanders NJ (2002) Elevational gradients in ant species richness: area, geometry, and Rapoport's rule. Ecography 25: $25-32$

Scarabino F (2004) Lista sistemática de los Gastropoda marinos y estuarinos vivientes de Uruguay. Comun Soc Malacol Urug 8:305-346

Weisberg S (1985) Applied linear regression, 2nd edn. Wiley, New York

Submitted: May 21, 2007; Accepted: May 28, 2008

Proofs received from author(s): August 26, 2008 